\title{
Assessment of Whole Class Instrumental Music Learning in England and the United States of America: An International Comparative Study
}

Whole class instrumental learning of musical instruments takes place when a group of students in a regular classroom setting all learn to play a musical instrument at the same time. In some instances, this involves a single instrument, such as the trumpet, in other cases, they learn to play two or more different instruments from the same instrumental family, for example the trumpet and trombone, whilst in different contexts they learn to play a wider variety and range of instruments, for example the flute, clarinet, trumpet, trombone, and snare drum. This practice is relatively new to Britain, but in other countries such as the United States, it is far more common. For this reason, these two countries offer a useful international comparison of this type of music learning. In this paper, the authors consider teaching, instructional, and assessment practices from their respective international contexts: England and the USA. This comparison of instrumental music education reveals an underlying difference in elementary or primary general music education in terms of the curricular practices in each country.

At the outset, it is important to note that there are significant differences in the ways in which terminologies are used between the two educational systems. As this paper is jointly authored by academics located in each of the jurisdictions concerned, we have tried to use words which are apposite for both, but there remain many differences. For example, in the American context 'instruction' is used unproblematically, whereas in England the word 'teaching' would more normally be employed; instruction carrying sometimes pejorative connotations of teacher monologue. In a similar fashion, the notion of assessment itself carries different baggage when used in each educational system, as we shall explore. Aspects of linguistics are clearly relevant here:

Linguistic theory frequently employs the distinction 'denotation' and 'connotation'. The term 'denotation' is widely equated with the literal meaning of a sign... 'Connotation', on the other hand, is employed simply to refer to less fixed and therefore more conventionalized and changeable, associative meanings, which clearly vary from instance to instance and therefore must depend on the intervention of codes. (Hall, 1993 p.512)

One of the aims of our work together is to endeavour to disentangle some of these linguistic differences, as they can have a substantial impact, and can really matter when talking about matters as important as assessment and music education on the international stage. This article concerns itself with these topics, but in order so to do, first we need to understand what the two national contexts entail, both in terms of music education and assessment. 
Simple as it may seem, however, even these two terminologies are problematic in international contexts (Fautley \& Murphy, 2015; Fautley \& Colwell, 2012).

Instrumental music teaching and learning normally takes the form of a band, orchestra, or other musical ensemble. Because these groups typically comprise a variety of instruments, teachers need to differentiate teaching/instruction by applied instrument while directing the entire group. Students primarily demonstrate their cognitive and psychomotor learning through performance. Assessment of student learning is therefore somewhat different than might normally expected in a general music class. Below, we discuss pedagogic and assessment approaches to instrumental music education as adopted in each of the two countries in terms of the corresponding national educational standards and systems.

\section{The American Context}

In the United States, schools regularly offer instrumental music programs after grade 5 (Grade 5 equates to Year 6 in the British system). As students transition from the elementary grades (Pre-Kindergarten or Kindergarten to grade 5) into the middle grades (grades 6 to 8), they have the option of studying a band or orchestral instrument. Students' elementary general music education lays the foundation for experiencing and understanding melody, rhythm, form, and other musical elements by singing, playing classroom instruments, and movement. This fundamental study during the elementary grades prepares them to apply their knowledge and skills to a traditional band or orchestral instrument. Instrumental music teachers at the secondary level (in the middle grades and beyond) then build upon these musical fundamentals while they simultaneously apply them to teaching performance skills on band or orchestral instruments. Most of the instrumental music teaching and learning is therefore focused on the psychomotor skills required to play the instruments. For example, the brass and woodwind instruments require students have the proper embouchure while string instruments require accurate fingering and bowing techniques.

Many states in America have articulated state standards for music education that outline a sequential curriculum to provide for a seamless transition from elementary school to middle school. Ideally, the elementary, general music program includes instruction for students on instruments such as the soprano (descant) recorder, keyboard, and ukulele (Campbell \& Scott-Kassner, 2014). As beginning woodwind and string instruments, these two examples offer learners the chance to practice psychomotor skills, apply music literacy, and to perform for others. Seen by some as the culmination of general music instruction, playing pre-band instruments is a successful transition to the middle school (grades $6-8$ ). 
Although whole-class instrumental music in American schools has a longer history than that in the Britain, bands and orchestras date back only to the early twentieth century. Prior to the 1920's, instrumental music education in the American school system was basic (Keene, 1982). Military traditions linked to the Civil War (1861 - 1865) and the First World War (1914 - 1918) provided a lineage for these ensembles. Despite humble beginnings, school band programs began to gain popularity and membership. By 1923, the Music Supervisors National Conference (predecessor to the Music Educators National Conference and the National Association for Music Education) subsequently adopted and promoted the values of instrumental music education in American schools. In the following decades, bands developed in schools across the country (Mark \& Gary, 2007). As Humphreys, May, and Nelson reported in their 1992 overview of research on school music ensembles, participation in school musical groups enjoys support of parents, administrators, and society in general.

Instead of orchestra or alternative ensembles, instrumental music education in the United States tends to emphasize band ensembles. These most often take the form of concert bands, marching bands, and jazz bands, comprised of brass, woodwind, and percussion instruments. Although some schools offer orchestral ensembles, bands feature more prominently in the secondary American musical landscape. Instruction in these ensembles highlights performance technique (psychomotor skills) along with group cohesion. Connotations of these ensembles are frequent ensemble performances for a variety of school and civic events, such as half-time at American football shows, holiday parades, school assemblies, and public concerts.

Consequently, directors need to ensure the performance quality of their groups for a wide range of audiences and events.

Much of the focus American instrumental music teachers have during beginning instrumental instruction highlights proper tone production, posture, and other specific psychomotor skills. American instrumental music teachers not only guide their students in developing the necessary playing techniques, but they also direct or conduct their ensembles. These directors therefore fulfil multiple roles. For this reason, the corresponding assessment practices need to address both the technique and musicianship in students' performances.

During the middle school years, instrumental music programs participate in Music Performance Assessments (MPAs), often in band or orchestral festivals. This whole-group assessment practice mirrors whole-class instrumental instruction on similar or dissimilar instruments. Often presented as group rehearsals, corresponding instruction involves a group of students with a range of knowledge and skill levels, playing a variety of instruments. 
Ideally, the ensemble director is able to supplement whole group rehearsals involving dissimilar instruments with smaller groups of students who play similar or the same type of instrument. These sectional rehearsals provide for more focused, specific skill development needed to perform the ensemble literature.

As suggested by their name, MPAs focus on performance skills. More specifically, they typically address components of ensemble performance such as: tone, intonation, technique, rhythm, balance, blend, and musicianship. Judges rate each ensemble's performance on prepared and unprepared music (termed sight-reading). Using a rubric or other grading scale, each ensemble receives feedback about their performance with respect to each performance element. Results may serve as either formative or summative whole-group assessment, depending on the group's performance schedule and expectations. Ratings are either norm or criterion referenced, according to the festival scope and protocol.

Although MPAs vary by state in America, instrumental music teachers regularly administer and manage these assessments through their corresponding music educator associations. While MPAs address details of performance quality and execution, they do not encompass other expectations of music education in the United States. For example, some state standards expect teachers to include student understanding of historical, global, and interdisciplinary connections as contextual relevance. In addition, MPAs address only the performance of the recently adopted National Core Arts Standards (NCAS). Because performance excellence does not necessarily indicate corresponding levels of understanding, other parallel assessment measures would offer a more complete picture of student learning. Because standards guide instruction and assessment should correspond to the intended instructional outcomes (Campbell \& ScottKassner, 2014; Conway, 2008), it is informative to summarize the recent changes in American national music education standards.

In 2014, the National Association for Music Education (NAfME) transitioned from a set of nine National Standards for Music Education, to those articulated by the National Coalition for Core Arts Standards. Consistent with other arts disciplines, the four National Core arts Standards (NCAS) include creating music, responding to music, and connecting with other disciplines, in addition to performing music. These three processes of engaging with music are central to the revised national standards, as opposed to more prescriptive activities and proficiencies listed in the original nine standards.

Important to these new standards is their conceptual framework, Understanding by Design (Williams \& McTighe (2005). This curricular 
approach features essential questions and enduring understandings in order to base instructional models on intended outcomes and learning goals. At present, however, the majority of music teacher educators are unfamiliar with this conceptual framework. While some are in the process of implementing it in their teacher education programs, most American music educators have not embraced the NCAS (Johnson et al., 2015). Furthermore, instrumental music teachers generally base instructional decisions on their own values instead of national standards (Gossett, 2016). Consequently, NAfME has sponsored an on-going pilot-testing project to offer music teachers a set of Model Cornerstone Assessments that can assist in planning, delivering, and assessing music instruction.

In essence, American instrumental music education focuses on building upon students' elementary understandings and experiences with musical elements (i.e. rhythm, melody, harmony, form, timbre, texture, dynamics, and form) through the medium of an instrumental performance ensemble. As indicated by title of the applied music series, Teaching Music through Performance (Blocher et al., 2007), instrumental music teaching focuses on performance as the vehicle for engaging students in musical study. The corresponding aims and outcomes for student learning vary, but instrumental music teachers' generally seek to promote lifelong musicianship, as well as positive social experiences, independent musicianship, and musical excellence through performance (Gossett, 2016).

\section{The English Context}

The situation in England is somewhat different from that pertaining to American schooling. In England, whole class instrumental learning often takes place in primary schools under what is known as the 'wider opportunities' scheme, also known by a variety of other names, including 'first access', 'whole class instrumental and vocal teaching' and 'whole class ensemble teaching'. For the purposes of simplicity, this article will refer to it as whole class ensemble teaching (WCET)

WCET in England as a widespread activity has been taking place in some areas for a number of years, but its widespread adoption as a pedagogic modality can be seen to have arisen as a result of the National Plan for Music Education (NPME) (DfE \& DCMS, 2011). The NPME established the notion of music hubs in England, which are area-based groups of organisations,

....such as local authorities, schools, other hubs, arts organisations, community or voluntary organisations - working together to create joined-up music education provision, respond to local need and fulfil the objectives of the hub (Arts Council website) 
There are 123 separate music hubs in England (Arts Council website), and each of these music hubs is responsible for delivering WCET music lessons in primary schools, usually to year 4 children (aged 8-9 years). Such lessons are delivered using musical instruments, by a visiting specialist music teacher. What often happens is that a class-set of instruments is supplied to a school, sometimes all the same instrument, or sometimes a range of instruments from the same family, and these are used as the basis for music education with that class. Different models of this are to be found, with the various music hubs adopting their own local variations on it. In some cases children receive lessons for a term on an instrument, and then swap to a different instrument in the next term, in other cases children stay on the same instrument for a whole year. What marks this programme out is that it is meant to be fully inclusive, with all of the children in the class learning music at the same time. In many schools the regular class teacher also learns alongside the pupils.

Where issues arise with regard to WCET music tuition, and which have a significant bearing therefore on the assessment thereof, is with how it conceptualised, and therefore delivered. The key issue here is that an unintentional fault-line has been created which is a rift between policy and practice. Many music hubs' policy view is that WCET is a means of delivering National Curriculum music lessons, in other words a generalist music education through the medium of an instrument. For example, Birmingham Music Service (BMS) describes WCET in this fashion:

The programme is delivered, to all pupils in every Year 4 class, by a Music Service teacher working in close partnership with the class teacher.

A typical session lasts for 45 minutes per class every week for the full year. Main elements of the National Curriculum for Music are covered including singing, musical games and opportunities for composition and improvisation. (BMS website)

Many other music hubs have similar statements on their pages.

However, in practical and operational terms, the words in italics used above, through the medium of an instrument are significant here, as the operationalisation of WCET in the classroom is often by instrumental music teachers, who sometimes have a personal view that WCET is about whole class lessons which focus on learning how to play an instrument. Here are two contrasting comments from two different WCET teachers: 
First access doesn't work, as the children don't get far enough on their instruments. They would be better off not doing it, and [schools] just choosing those who want to learn to play. (Teacher A, comment)

If you think it's about learning to play your instrument you will get frustrated, this [WCET] is - or should be - whole class music lessons using instruments as the way in (Teacher B, comment).

These difference can be traced back to the issue described above, the coexistence of a National Curriculum and a National Plan, which creates in and of itself internal and external policy and practice issues. As Gary Spruce has observed:

The NPME thus privileges and promotes a relatively limited way of musical knowing, rather than the multiple ways of knowing which characterise inclusive music education practices (Spruce, 2013 p.29)

What this means is that there is a dichotomy when thinking about teaching and learning music in the school situation. Music hubs will be concerned with the NPME, but need to think about the NC when working in schools; schools need to think about the NC, and the impact of the NPME may be considerably lighter upon them.

These differences matter, as the place and role of assessment in WCET music lessons can often be seen to follow one of a number of modalities, some of which co-mingle with each other:

1. Assessment is based on National Curriculum levels of attainment, or whatever schools have replaced them with, alongside terminologies employed so that they are re-phrased for suitability

2. Criterion specific assessment terminologies are employed, so that musical progress is assessed using the instrument as a means of understanding music

3. External examinations are employed, such as ABRSM music medals (ABRSM website) or Trinity College music tracks (Trinity College website)

4. A mixture of the above.

National Curriculum levels and their utilisation require some explanation in an international context. Up until September 2014 schools in England had to teach music as a compulsory National Curriculum subject, which had statutory assessment levels associated with it. These levels were holistic statements of pupil attainment, and, at their original inception, were intended to be used only at specified points in the education of young people, namely aged 7,11 , and 
14 years old. Over time it became customary to use these assessment level statements as measures of pupil work with increasing frequency. It is important to observe that these $\mathrm{NC}$ levels are measure of general musical attainment in the classroom. To illustrate this here is the text of the level 4 statement, this was the attainment expectation of 11 year olds as they transfer from primary to secondary school:

Pupils identify and explore the relationship between sounds and how music reflects different intentions. While performing by ear and from notations, they maintain their own part with awareness of how the different parts fit together and the need to achieve an overall effect. They improvise melodic and rhythmic phrases as part of a group performance and compose by developing ideas within musical structures. They describe, compare and evaluate different kinds of music using an appropriate musical vocabulary. They suggest improvements to their own and others' work, commenting on how intentions have been achieved. (QCDA website)

As can be seen, to apply this generic statement of musical attainment to something as specific as learning to play a musical instrument is going to be problematic. Added to this is the fact that teaching and learning often takes place in a whole-class situation via a peripatetic teacher who may only be in the school for an hour each week, and there are clear issues for operationalising any assessment system. What it does mean is that the teaching and learning of music needs to include assessment of the three components of performing, composing, and listening. It is in this area that much work is taking place on a nationwide basis in an endeavour to address these complex issues. In a similar fashion the use of ABRSM or Trinity examinations means that the young people are focussing in on learning music via learning to play an instrument. The ramifications of mapping these onto National Curriculum levels are not entirely straightforward, which again has the potential to create a somewhat bifurcated system, but with the removal of the requirement to assess and report using levels will hopefully work in teachers' favour.

\section{Curriculum}

As can be seen from the American and English descriptions, there are clear differences between the two jurisdictions with regard to curriculum. With the reduction in applicability of the National Curriculum in English schools, allied with the nature of peripatetic music teaching, there will inevitably be significant inter-school differences. For example, a school can have its WCET built around the guitar, whilst in a neighbouring school it is brass instruments that form the core element. Although the musical learning outcomes may be similar in each case, the means to this end will clearly have differed, as the 
instrument-specific complexities of guitar and brass have little technique in common.

In the United States, instrumental music programs have more consistency throughout the country than do those in England. Most often taking the form of band ensembles, these groups in American schools offer the same basic instrumentation (woodwinds, brass, and percussion) regardless of location. Although programme size and quality varies considerably, the instrumental music curriculum is largely the same, guided by state-level standards. Each of the fifty United States establishes its own set of instrumental music standards, coordinated with the National Association for Music Education (NAfME). In 2014, that organization patterned its updated standards on the National Coalition for Arts Education to align with the Twenty-First Century Skills of Communication, Collaboration, Creativity, and Critical Thinking (Smith \& Hu, 2013). The resulting categories of the National Core Arts Standards (NCAS) standards are: perform, respond, and create. As applied to instrumental music education, students are expected to demonstrate a range of knowledge and skills. Those include performance, but also are expanded to encompass reflective and creative activities.

In a larger sense, we may understand the differences between the two countries' approaches to instrumental music education in terms of curricular sequence and organization. As summarized earlier, the focus of American instrumental music education is on extending students' understandings and experiences with the musical elements at the elementary level through instrumental performance. Practical strengths of this approach include deepening and furthering students' work with music from the elementary to the middle grades and beyond. Weaknesses of this arrangement are involving a minority of the student population who have the interest and availability to participate in an instrumental ensemble, for a variety of reasons (Elpus \& Abril, 2011). In contrast, instrumental music education in British schools centres whole-class instruction via WCET. This teaching begins earlier (at age 8 or 9 vs. 12 or 13) and may substitute for what American music educators would recognize as general music. Strengths of this approach are including every student in instrumental study, instead of a selected subset of the class. Weaknesses include limiting students' music education at this age to instrumental study, instead of varied activities designed to engage all learners.

\section{Assessment}

Into this already complex mix we need to add the challenges of assessment. One of the key questions to be asked here is 'who is the assessment for?' (Fautley, 2010). The answers to this seemingly innocent question uncover an otherwise hidden world of complexities. 
In England there are multiple answers to the question of 'who is the assessment for?'. Certainly the pupils will be one strand of this, with assessment designed to help them improve. But in England the existence of league tables which are published in national and local press means that schools are very concerned that their public facing assessments are always the highest they can be, so as to facilitate league table success. Although music does not figure much in these at present, headteachers are very aware that time away from the core subjects - maths and English - could have a detrimental effect upon this. This means that with the complexities of constructing teaching timetables for peripatetic staff visiting may schools, some schools may not want their pupils to miss what they see as prime learning time to go to music lessons. This can reduce the availability of such musical learning opportunities for the young people involved.

In the United States, school administrators similarly track academic grades and related achievement measures such as state test scores. With regard to instrumental music, however, there is not the same intensity of scrutiny as in England for academic ratings. In fact, music is a "non-tested" subject in many American schools, in contrast to English, mathematics, and other academic subjects. Researchers have assembled a considerable body of scholarship on the question of how missing non-music classes affects academic achievement (Hodges \& O'Connell, 2005). Those findings demonstrate that participation in "pull-out" programs to allow for instrumental music lessons does not negatively affect student academic learning (Corral, 1998; Cox, 2001; Dryden, 1992; Engdahl, 1994; Kvet, 1985). More often, American music educators responsible for instrumental ensembles focus on MPA ratings and festival scores because these serve as important external incentives in the form of trophies and other extrinsic motivators.

Instrumental music teachers in the United States are primarily focused on performance excellence. Perhaps because school administrators and parents expect instrumental music ensemble to deliver quality performances for civic and athletic functions, those ensemble directors place an emphasis on summative measures as performances and highlight psychomotor skill achievement of the entire group. While some musical creativity and critical reflection may naturally contribute to successful musical execution, current assessment tools in American instrumental music are largely performancebased. With the recent update to the national standards for music education endorsed by NAfME, American music educators may begin to include other non-performance skills as formative and summative assessments that contribute to fostering more well-rounded student musicians.

Lessons (to be) Learned 
While social and cognitive goals are often implied with successful large-group performances, individual students' conceptual understanding is not. From a practical perspective, producing large group performances by skilled ensembles is a powerful advocacy tool in the American context. Concerts, parades, and other exhibitions of student ensembles can effectively demonstrate student learning to a wide spectrum of audiences at key opportunities. At the same time, high-profile performances demonstrate the school's civic engagement and participation in community events. Shortcomings of this type of performance as assessment include the lack of attention to assessing individual students' learning and a short-lived focus on performances.

Because the English system of music education has more of an explicit focus on composition and less prescribed activities at the elementary or primary level, American teachers might also adopt practices to address creating music (vis-à-vis composition or improvisation) in tandem with re-creating it in wellrehearsed performances. While promoting student collaboration, American music educators would be wise to adopt or adapt elements of the British system, they could more broadly promote Twenty-First Century Skills, e.g. Communication, Collaboration, Creativity, and Critical Thinking (P21, n.d.). These skills reach across the curriculum and provide instrumental music teachers with a framework to articulate the importance and impact of instrumental music study and of music education in general. By combining concert performances with individual reflection and attention to aesthetic growth, American instrumental music teachers may develop more sensitive student-musicians and life-long learners (Blocher et al., 2007).

Our research shows that it would be helpful to rethink the nature of instrumental music education on both sides of the Atlantic. By reconsidering what each approach espouses and operationalizes, we might better align the corresponding assessments. If a system is predicated upon learning to play an instrument as the sole feature of musical education in young people, then clearly a very different set of task outcomes is required from one where composing is included. This opens up a significant debate concerning music education, which will require much deliberation, as in these times of austerity budgets, there is a real and present danger that administrators and budget holders will take decisions that can adversely affect music education provision in schools. By comparing and contrasting different systems of music education, we may clarify our own goals and recognize the most promising ways to adapt and adopt best practices for the benefit of teachers and their students.

\section{References}


ABRSM Website: http://gb.abrsm.org/de/our-exams/what-are-music-medals/ Accessed 12/15

Arts council website: http://www.artscouncil.org.uk/what-we-do/cyp/musiceducation/music-education-hubs/ (accessed 12/15)

Birmingham Music Service website:

http://servicesforeducation.co.uk/index.php/Music-Services/wholeclass-instrumentalteaching.html?option=com content\&view=article\&id=61\&catid=15\&lte mid=254 (accessed 12/15)

Blocher, L., Miles, R. B., \& Corporon, E., Lautzenheiser, T., Lisk, E. S., \& Cramer, R. (2007). Teaching music through performance in band (Vols. 1 - 10). GIA Publications.

Campbell, P. S., \& Scott-Kassner, C. (2014). Music in childhood. Stamford, $\mathrm{CT}$ : Schirmer.

Conway, C. (2008). The implementation of the national standards in music education: Capturing the spirit of the standards. Music Educators Journal,94(4), 34-39.

Corral, S.J. (1998). A comparison study of the California Test of Basic Skills between fourth and fifth grade instrumental music pullout students and students not involved in the instrumental music program. (ERIC Document Reproduction Service No. ED430013)

Cox, R. W. (2001). Effects on academic achievement for fifth-grade students in a band pull-out program. (Masters thesis, California State University, Fresno). Masters Abstracts International, 40 (01), 26.

DfE \& DCMS (2011) 'The Importance of Music - A National Plan for Music Education'. London, Department for Education and Department for Culture, Media, and Sport.

Dryden, S. (1992). The Impact of Instrumental Music Instruction on the Academic Achievement of Fifth Grade Students. (ERIC Document Reproduction Service No. ED368634)

Elpus, K., \& Abril, C. R. (2011). High school music ensemble students in the united states a demographic profile. Journal of Research in Music Education, 59(2), 128-145.

Engdahl, P. M. (1994). The effect of pull-out programs on the academic achievement of sixthgrade students in South Bend, Indiana. (Doctoral dissertation, Andrews University). Dissertation Abstracts International, 55 (05), 1179A.

Fautley, M. (2010) Assessment in Music Education, Oxford, Oxford University Press.

Fautley, M. \& Colwell, R. (2012) 'Assessment in the secondary school classroom'. In Welch, G. \& McPherson, G. (Eds), Oxford Handbook of Music Education, Vol. 1, pp. 478-94. New York, Oxford University Press. 
Fautley, M. \& Murphy, R. (2015) What is music education? - Editorial. British Journal of Music Education, 32, 1, 1-4.

Gossett, J. (2016). An examination of the pedagogic values of band directors. Visions of Research in Music Education, 29. Retrieved from http://www.rider.edu/ vrme

Hall, S. (1993) 'Encoding, decoding'. In During, S. (Ed), The cultural studies reader, pp. 507-17. London, Routledge.

Hodges, D. A., \& O'connell, D. S. (2005). The impact of music education on academic achievement. The University of North Carolina at Greensboro. Retrieved August, 20, 2010.

Humphreys, J. T., May, W. V., \& Nelson, D. J. (1992). Research on music ensembles. In R. Colwell (ed.), Handbook of research on music teaching and learning (pp. 651 - 668). New York: Schirmer Books.

Johnson, D. C., Peterson, A., Spears, A., \& Vest, J. (2015). An Examination of "Understanding by Design" in the National Music Education Standards: Perspectives and Practices of Music Teachers and Music Teacher Educators. Presentation at the Symposium on Music Teacher Education, The Society for Music Teacher Education, Greensboro, NC.

Keene, J. A. (2010). A history of music education in the United States. Glenbridge Publishing Ltd..

Kvet, E. J. (1985). Excusing elementary school students from regular classroom activities for the study of instrumental music: The effect on sixth-grade reading, language, and mathematics achievement. Journal of Research in Music Education, 33(1), 45-54.

Mark, M., \& Gary, C. L. (2007). A history of American music education.Rowman \& Littlefield Education.

P21 (n.d.). Partnership for 21st Century Learning. Retrieved from http://www.p21.org/ September 15, 2015.

QCDA Website: http://www.teachfind.com/qcda/attainment-target-musicsubjects-key-stages-1-2-national-curriculum-2 (accessed 12/15)

Smith, J., \& Hu, R. (2013). Rethinking teacher education: Synchronizing eastern and western views of teaching and learning to promote 21st century skills and global perspectives. Education Research and Perspectives (Online), 40, 86-108. Retrieved from http://search.proquest.com/docview/1462385468?accountid=29025

Spruce, G. (2013) 'Participation, inclusion, diversity and the policy of English music education'. In Harrison, C. \& Mullen, P. (Eds), Reaching Out: music education with hard to reach children and young people. , London, Music Mark

Trinity College website: http://www.trinitycollege.com/site/?id=1068 Accessed $12 / 15$

Wiggins, G. P., \& McTighe, J. (2005). Understanding by design. ASCD, Alexandria, Virginia 